\title{
A PRACTICAL APPROACH TO THE ESTIMATTION OF POLLUTANT LOAD FROM OPTICAL SENSOR MEASUREMENT
}

\author{
Minghuan LIU 1 , Tadaharu ISHIKAWA ${ }^{2}$, Kenji YOSHIMI ${ }^{3}$ and Eiji KUNIHIRO 4 \\ ${ }^{1}$ Student Member of JSCE, Doctoral Student \\ ${ }^{2}$ Member of JSCE, Dr. of Eng., Professor \\ ${ }^{3}$ Student Member of JSCE, Master Student \\ ${ }^{1}$ Dept. of Civil Engeering, Tokyo Institute of Technology, Nagatsuda 4529, Yokohama 226-8502, Japan \\ 2,3 Dept. of Environmental Science and Technology, Tokyo Institute of Technology, Nagatsuda 4529, Yokohama \\ 226-8502, Japan \\ ${ }^{4}$ M. Eng., Chuo 6-1-1, Hikari, Pref. Yamaguchi, 743-8501, Japan
}

\begin{abstract}
Reduction and control of pollutant load from non-point sources is a key issue to improve the water condition in lakes. In the monitoring of water quality in rivers for this purpose, continuous measurement is required because the pollutant load from non-point sources is highly variable in a process of rain runoff. In practice, however, this requirement is often contradictory to the requirement of data accuracy.

This paper proposes a new idea on the "concept of measurement" in order to develop a "dynamic measurement" of the pollutant load. The point of authors' idea is to use empirical relations found in the field as positively as possible, even if we don't have any scientific reason for the relation. Then, results of a field experiment on the pollutant load monitoring are presented to show the feasibility of the idea.
\end{abstract}

Key Words : monitoring, pollutant load, empirical correlation, optical sensor

\section{INTRODUCTION}

Reduction and control of pollutant load from non-point sources is a key issue to improve the water condition in lakes. Clean Lake Law was revised in 2005, stressing the importance of watershed management and monitoring of pollutant load in rivers to control the non-point sources in the watershed $^{1)}$. In the monitoring, frequent or continuous measurement of water quality is required because the pollutant load from non-point sources is highly variable in a process of rain runoff $^{2}$. Chemical analysis of water samples is not suited for this purpose because of the restriction of labor and budget. Robotic monitoring station is not adequate either because it is too expensive to develop widely in the watershed.

Recently, continuous measurement of water quality is tried in rivers for some items of water quality by using immersed-type optical sensors; particulate phosphorus with a turbidity meter ${ }^{3)}$, $C h l-a$ with a fluorometer ${ }^{4)}$ and dissolved $C O D$ by a UV-meter ${ }^{5)}$. These measurement techniques contain some empirical factors to be calibrated at each site, and have some errors due to the fluctuation of site conditions. Because of the defects, they are often regarded as of lower value than chemical water analysis. However, they have a strong point of getting continuous data, and have a large potential to be used in the monitoring of the river water quality.

Accuracy and reliability have been the most requirements in any kind of measurement. Recently, however, data resolution in time and space becomes required to capture the dynamic feature of the environment. The two requirements are often contradictory to each other in practice; taking the one, losing the other. In order to satisfy the both, we must bear a lot of labor and cost. The authors think that "some paradigm shift in measurement" will be necessary to develop the dynamic monitoring of the environment. This paper proposes a step for shifting the "concept of measurement", and discusses the potential of a practical method to monitor the pollutant load in rivers by using optical sensors. 


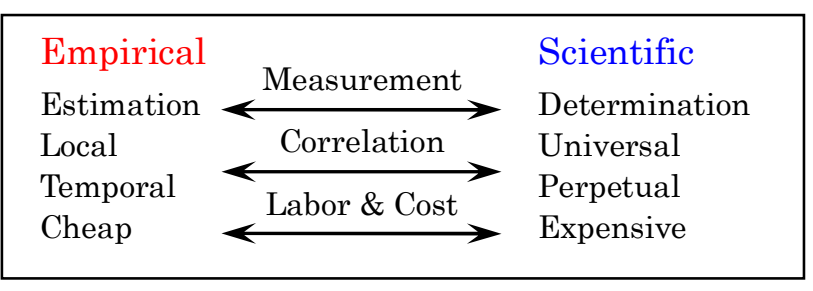

Fig.1 Scientific and empirical measurements

\section{STANDPOINT OF THIS STUDY}

The measurement in engineering has a wide range. On one hand, there are theoretically strict measurements supported by scientific evidences such as a velocity measurement based on the theory of Doppler Effect. On the other hand, there are measurements based on totally empirical relations such as the measurement of river flow rate based on so-called $H-Q$ relation. How can we arrange these different types of measurements?

The authors consider as follows ${ }^{6}$ : In practice, it is often difficult to measure directly what we want to know. Then, we try to find a correlation between what we want to know and what we can measure. For example, a classical thermometer does not show the air temperature itself but shows the volume change of mercury. Because the volume of the mercury has a high correlation with temperature, we can estimate the air temperature with the device.

There is a variety of correlations that we use for measurement. In the case of ADCP, the correlation is supported by a theory of Doppler Effect although data scatters around it because of some practical reasons. In the case of $H-Q$ correlation, it is totally empirical and changeable depending on the conditions of river channels. The variety of measurement techniques comes from the variety of correlations that we use for measurement.

Measurement techniques supported by purely scientific relation is called "scientific measurement" for convenience herein, and those supported by totally empirical relation is called "empirical measurement" herein. The former is universally reliable at any place at any time, while the latter is not. Fig. 1 shows the comparison of these two kinds of measurements.

With the development of modern technology, a variety of measurement devices are supplied. Most of the ones used in laboratory are classified into scientific measurements, and field measurements contain many empirical ones. Even if a scientific measurement is available in a field experiment of science, it is often not practical in the monitoring of the environment because it costs labor and money.

In brief, as long as we insist on scientific knowledge and explanation, field measurement is very restricted. Now, why don't we discard a paradigm "more scientific, then better"? Why don't we take empirical measurements more positively? Even when the basic relation for measurement exists only locally or temporally, isn't it all right if we can estimate what we want to know?

\section{OPTICAL SENSOR MEASUREMENT}

So-called $L-Q$ method is a typical empirical measurement to estimate the pollutant load in a river. It assumes that the river flow rate $(Q)$ is a single factor to determine the pollutant load $(L)^{7}$.

$$
L=f(Q)
$$

The assumption is based on a simple fact that pollutant load increases during flood event. Many authors discussed the errors of this method and concluded that the accuracy is not very high ${ }^{3}$. However, $L-Q$ method has a strong point that it can estimate a time series of $L$ without much labor; as a result, the method is still used widely in practice.

Keeping its merit, the method can be extended as follows: Select a set of factors that we can easily get their time series $\left(X_{1}, X_{2}, X_{3} \cdots\right)$, and assume the pollutant concentration can be determined by them.

$$
C=f\left(X_{1}, X_{2}, X_{3} \cdots\right)
$$

We can write the pollutant load as a product of the concentration and the flow rate,

$$
L=C \times Q=f\left(X_{1}, X_{2}, X_{3} \cdots\right) \times Q
$$

$L-Q$ method is the simplest form of Eq.(3) with only factor $X_{1}$ as $Q$. But, here we take multiple factors $X_{j}$, expecting their time series can be obtained from measurements.

The load of Suspended Solid (SS) or Total Phosphorous (TP) is sometimes estimated based on this equation by using data of Turbidity $(T b)^{3}$. As particulate form is usually dominant in $T P$ in rivers, a high correlation between $T b$ and $T P$ can be expected. Taking $T b$ as the dominant factor $X_{l}$,

$$
L_{T P}=C_{T P}(T b) \times Q
$$

where $C_{T P}(T b)$ is decided empirically by field data.

Dissolved $C O D$ in sewage can be measured by the absorption rate of ultraviolet rays ${ }^{3)}$. Recently, an immersed-type ultraviolet $(U V)$ absorption sensor is developed for field measurement in rivers. The load of dissolved $C O D$ can be estimated by,

$$
L_{D-C O D}=C_{D-C O D}(U V, T b) \times Q
$$

where $U V$ is the absorption rate of ultraviolet ray, and $T b$ is added as a parameter to consider the effect of high $S S$. The correlation function $C_{D-C O D}(U V, T b)$ is obtained from regression analysis based on field experiment.

Eqs.(4) and (5) are supported by scientific evidences to some extent although the final form of 


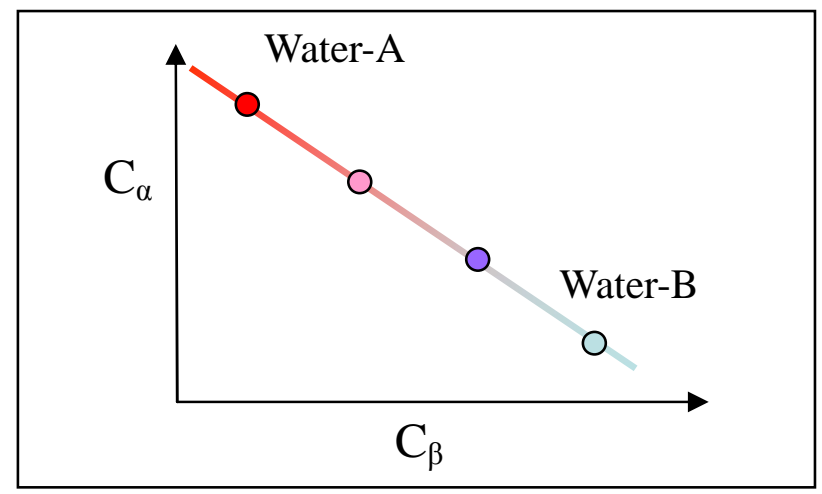

Fig.2 Sketch map of the two water sources

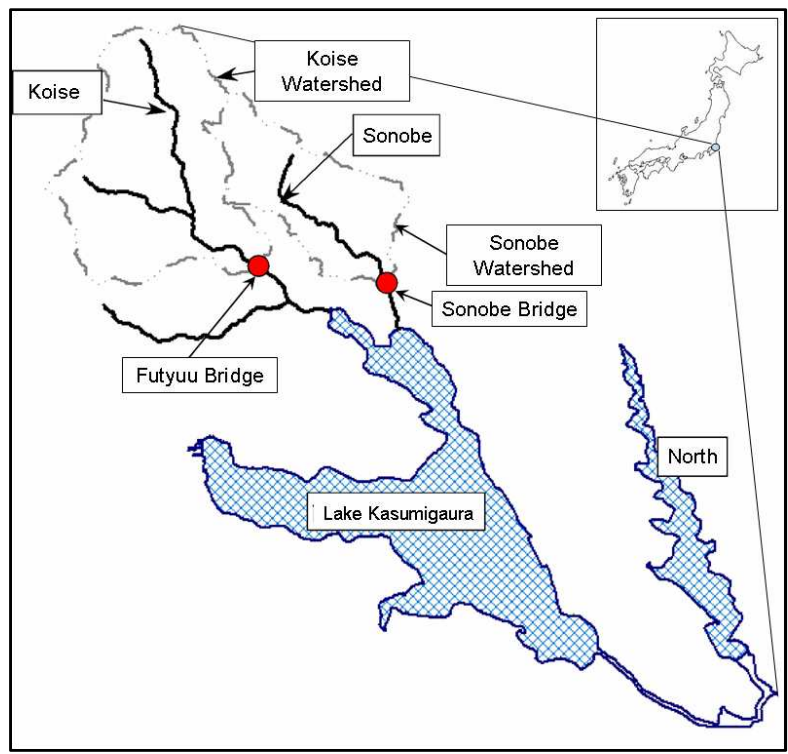

Fig.3 Location of measurement stations

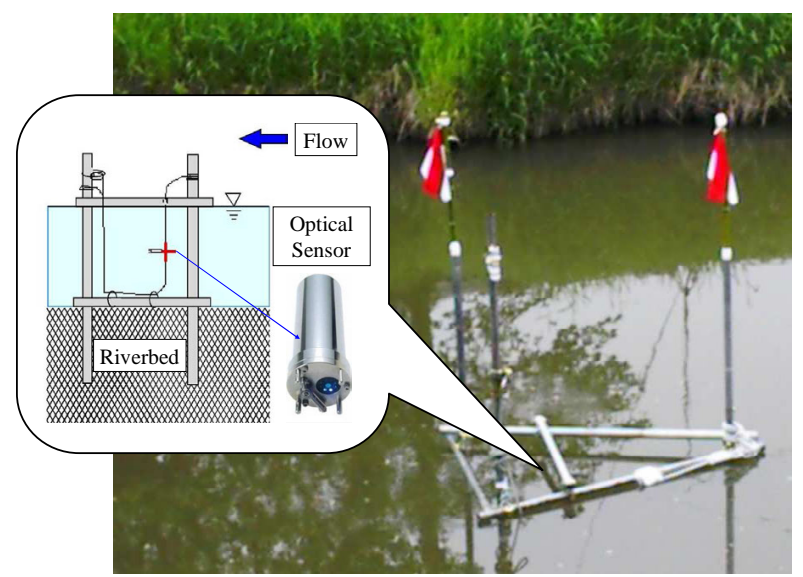

Fig.4 Experimental setup

the equations should be determined empirically. In this sense, they are between the scientific measurement and empirical measurement. The measurement of Chl- $a$ in water with fluorometer is the same kind one ${ }^{4)}$.

In this study, however, the authors are going to take empirical measurements positively as much as possible. They think very practically that any kind of correlation between $C$ and $X_{j}$ can be used to estimate $C$ from $X_{j}$, even if we don't have any scientific reason for the correlation.

As one example, let's assume the following situation (See Fig. 2): There are two kinds of water sources in a watershed, say A and B. The source A might be "surface runoff component" and B might be "shallow groundwater component", or A might be paddy fields and B might be forests. But, it is not a problem here if we can identify them or not. Now, consider two items of water quality, say $\alpha$ and $\beta$, and write their concentration as $C_{\alpha}$ and $C_{\beta}$. As shown in Fig. 2, we assume that the water from A has high $C_{\alpha}$ and low $C_{\beta}$, and the water from B has low $C_{\alpha}$ and high $C_{\beta}$. When the ratio of water $\mathrm{A}$ and water $\mathrm{B}$ changes in the process of rain runoff, the water quality observed at a downstream station moves on the straight line connecting the two points of $A$ and $B$ in the figure if there is no other practical factor.

Let's assume that we are interested in $C_{\alpha}$ but not $C_{\beta}$, but assume that $C_{\alpha}$ doesn't have any correlation with measurement items $X_{j}$ in Eq. (3); we cannot estimate $C_{\alpha}$ from $X_{j}$ directly. However, if $C_{\beta}$ that we are not interested in has a positive correlation with $X_{j}$, then we will find a negative correlation between $C_{\alpha}$ and $X_{j}$. This negative correlation is a "surface correlation" originated from a "local condition" of the watershed as shown in Fig. 2. In other words, it might collapse when the conditions of the watershed change largely.

If the natural and social conditions in the watershed are stable, we can use the surface correlation for the estimation of $C_{\alpha}$. Strict scientists may not like this kind of measurement. But in practice, it will be far better than having no data. In order to take this kind of empirical measurement, we must investigate if the surface correlation is stable or not, just in a same manner as $H-Q$ relation: River administration bureau usually checks the $H-Q$ relation once in a year and changes it if necessary. An action of the same kind must be needed for the empirical measurement of pollutant load.

\section{FIELD EXPERIMENT}

A field experiment was carried out to investigate the applicability of the above mentioned idea ${ }^{8}$. As shown in Fig. 3 and Fig. 4, immersed-type optical sensors (Compact-CLW: ALEC Electronics) were placed in the low water channel of the Koise River and the Sonobe River flowing into the Lake Kasumigaura from July 1st to December 1st, 2005. During the period, river water was sampled and analyzed 67 times in the Koise River and 57 times in the Sonobe River. The area of catchment and the land use are shown in Table 1. Table 2 shows the items of water quality analysis. 
(a)

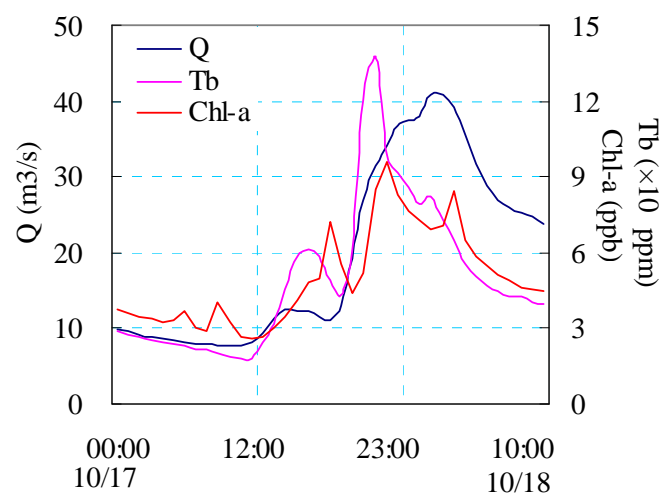

(c)

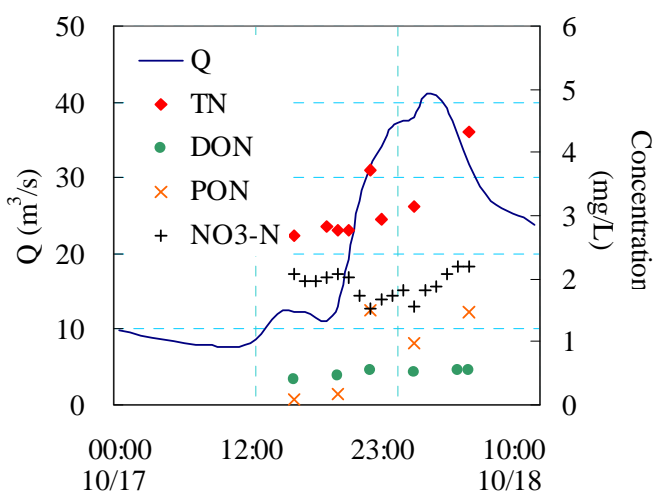

(b)

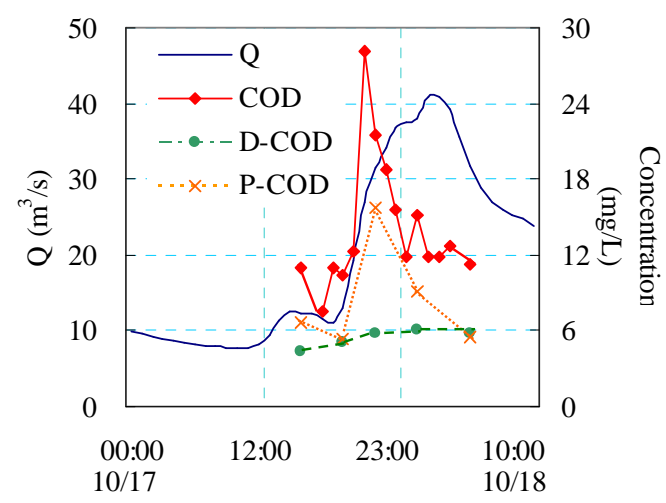

(d)

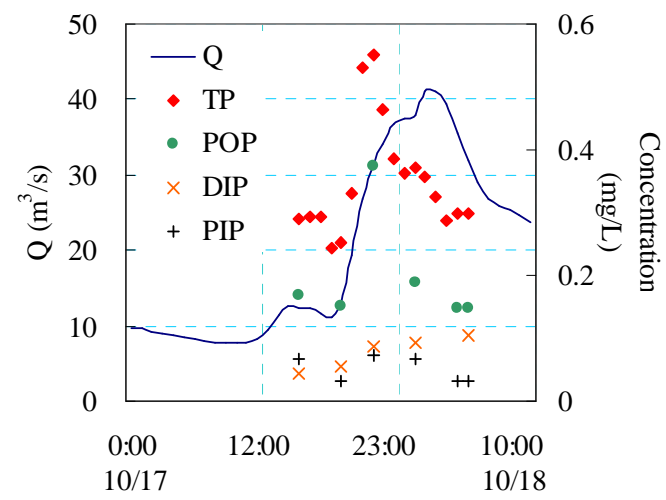

Fig.5 Water quality measurement during a flood of October 17th-18th, 2005 at the Koise River. (a) Optical sensor measurement; (b)-(d) laboratory analysis of water samples

Table 1 Characteristics of catchment areas

\begin{tabular}{|c|c|c|c|c|}
\hline \multirow{2}{*}{ Watershed } & \multirow{2}{*}{$\left.\begin{array}{c}\text { Area } \\
\end{array} \mathrm{km}^{2}\right)$} & \multicolumn{3}{|c|}{ Land use (\%) } \\
\cline { 3 - 5 } & Forest & Cropland & Other use \\
\hline \hline Koise & 147.4 & 50 & 40 & 10 \\
\hline Sonobe & 75.5 & 24 & 57 & 19 \\
\hline
\end{tabular}

Table 2 Analysis items of water quality

\begin{tabular}{|c|c|c|c|}
\hline Item & Mark & Item & Mark \\
\hline \hline $\begin{array}{c}\text { Chemical Oxygen } \\
\text { Demand }\end{array}$ & COD & $\begin{array}{c}\text { Particulate Organic } \\
\text { Nitrogen }\end{array}$ & PON \\
\hline Dissolved COD & D-COD & Nitrite Nitrogen & $\mathrm{NO}_{2}-\mathrm{N}$ \\
\hline Particulate COD & P-COD & Nitrate Nitrogen & $\mathrm{NO}_{3}-\mathrm{N}$ \\
\hline Total Organic Carbon & TOC & Ammonium Nitrogen & $\mathrm{NH}_{4}-\mathrm{N}$ \\
\hline $\begin{array}{c}\text { Dissolved Organic } \\
\text { Carbon }\end{array}$ & DOC & Total Phosphorus & TP \\
\hline $\begin{array}{c}\text { Suspended Solid } \\
\text { Volatile Suspended } \\
\text { Solid }\end{array}$ & VSS & $\begin{array}{c}\text { Dissolved Organic } \\
\text { Phosphorus }\end{array}$ & DOP \\
\hline Total Nitrogen & TN & $\begin{array}{c}\text { Dissolved Inorganic } \\
\text { Phosphorus }\end{array}$ & DIP \\
\hline $\begin{array}{c}\text { Dissolved Organic } \\
\text { Nitrogen }\end{array}$ & DON & $\begin{array}{c}\text { Particulate Inorganic } \\
\text { Phosphorus }\end{array}$ & PIP \\
\hline
\end{tabular}

Data of river flow rate was given by Ministry of Land, Infrastructure and Transportation. Compact-
Table 3 Specifications of the Compact-CLW

\begin{tabular}{|c|c|c|c|c|}
\hline \multirow{2}{*}{ Items } & \multirow{2}{*}{ Sensor type } & \multirow{2}{*}{ Range } & \multicolumn{2}{|c|}{ Wavelength (nm) } \\
\cline { 4 - 5 } & & & Emit & Receive \\
\hline \hline Chl-a & Fluorometry & $0 \sim 400 \mu \mathrm{g} / \mathrm{l}$ & 470 & $680 \sim 1000$ \\
\hline Tb. & $\begin{array}{c}\text { Infrared } \\
\text { backscatter }\end{array}$ & $0 \sim 1000 \mathrm{FTU}$ & 880 & 880 \\
\hline
\end{tabular}

CLW is designed to measure turbidity and Chl-a. Table 3 shows its specification. The measurement interval was set as 10 minutes in this experiment.

It must be noted that the purpose of this experiment is not to measure turbidity and $C h l-a$, but to estimate the water quality items listed in Table 2 from the signals of the sensors. In this sense, the term called "turbidity" for convenience in this paper is not turbidity itself but just a response of the water to the optical impact by the device, and it is considered as one of the parameters $X_{j}$ that appear in Eq.(3). So is the term called as "Chl-a".

Fig. 5(a) shows the signals from Compact-CLW during a flood in the Koise River, and Figs. 5(b)-(d) show the results of water analysis for major items. There is a time lag between the peak of discharge and the peaks of pollutant concentrations in Figs. 5(b)-(d). The latter were mostly caused by the particulate forms, having a correlation with turbidity in Fig. 5(a). 
(a)

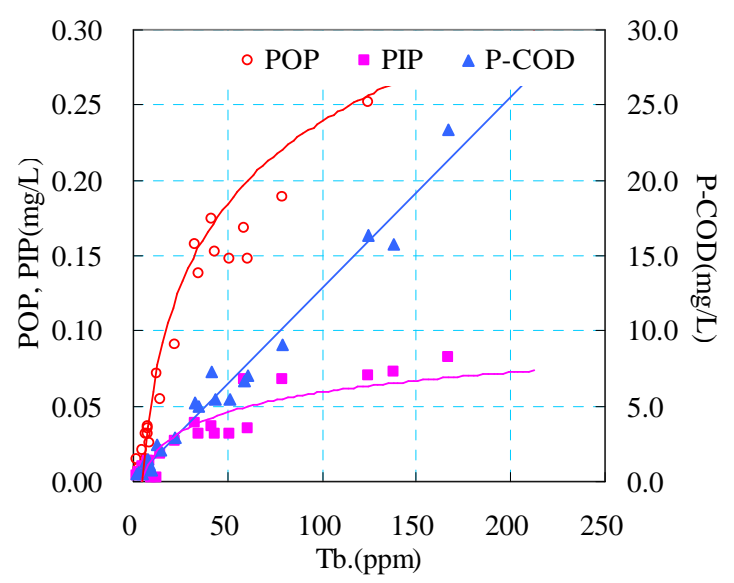

(b)

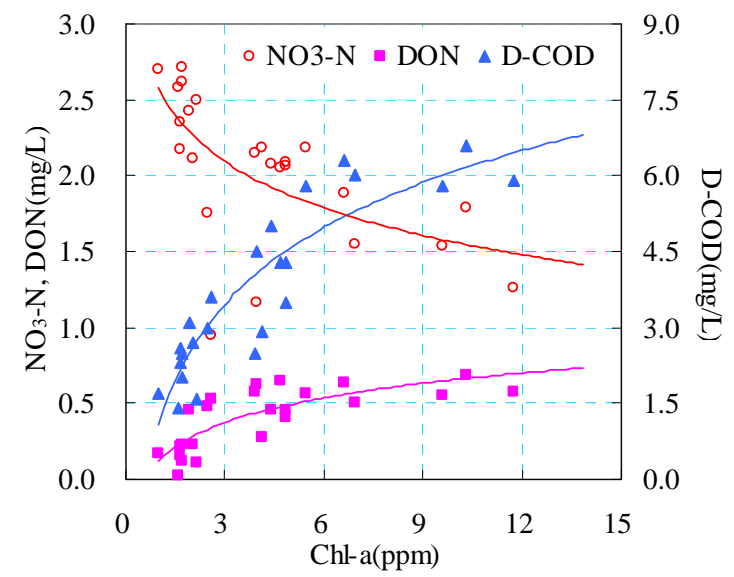

Fig.6 Relationships between Compact-CLW measurements and water analysis
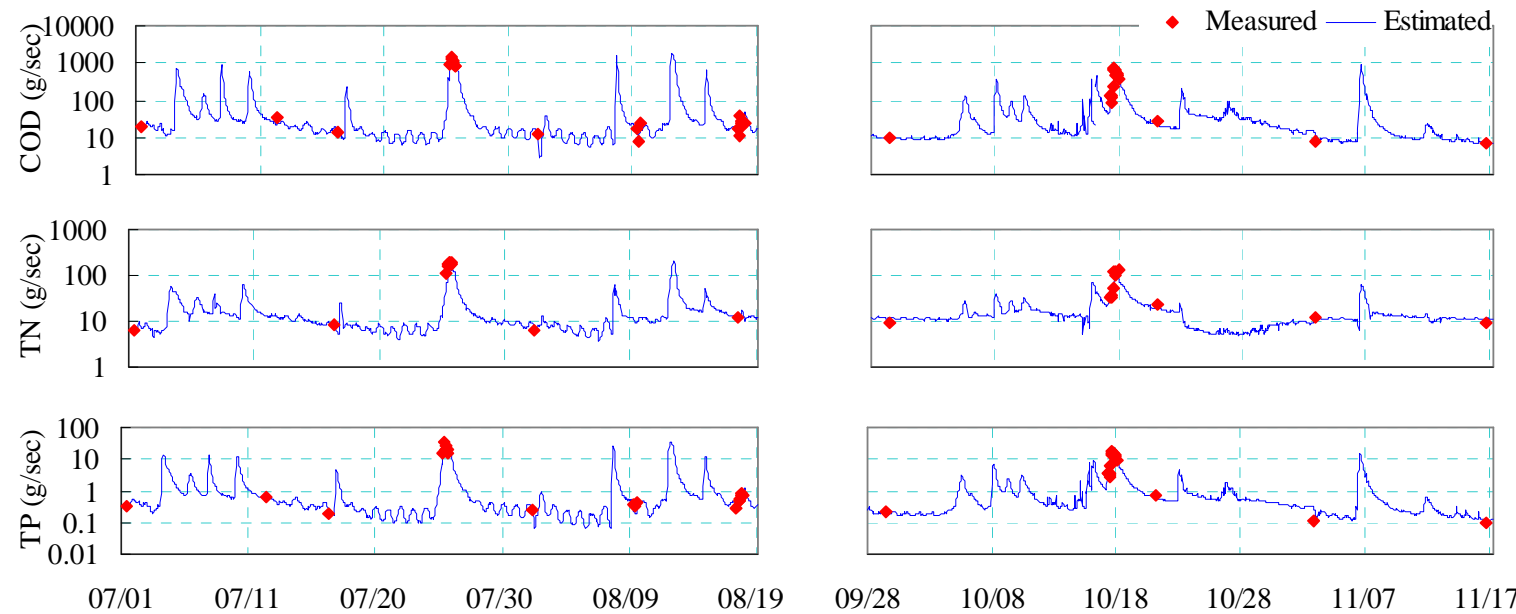

Fig.7 Time series of estimated COD, total nitrogen (TN) and total phosphorus (TP)

(a)
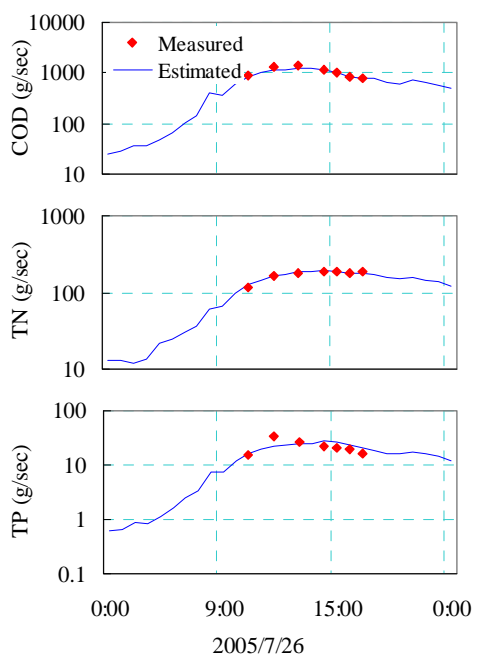

(b)
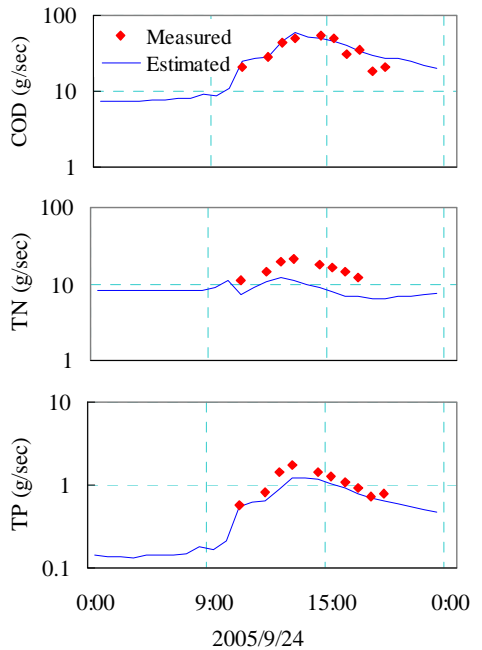

(c)
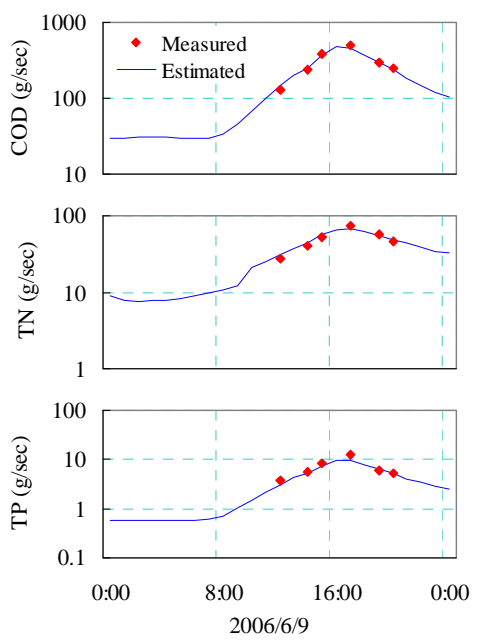

Fig.8 Comparison of measured and estimated COD, TN and TP

\section{RESULTS AND DISCUSSION}

Figs. 6(a) and (b) show the correlations between the signals from Compact-CLW and some results of water analysis. Because particulate substances have high correlations with $T b$ and dissolved substances with $C h l-a$, they are separately displayed in the figures. Here, it must be noted again that the terms " $T b$ " and "Chl- $a$ " are just the parameters $X_{j}$ contained in Eq.(3) in this paper. Keeping it in mind 
is important when we interpret what the data are suggesting. For example, the negative correlation of $\mathrm{NO}_{3}-\mathrm{N}$ with Chl-a in Fig. 6(b) does not mean that $C h l-a$ sensor captured the variation of $\mathrm{NO}_{3}-\mathrm{N}$ nor that $C h l-a$ has a negative correlation with $\mathrm{NO}_{3}-\mathrm{N}$ in actual. The data suggests that $\mathrm{NO}_{3}-\mathrm{N}$ increased when some thing captured by the fluorometer of Comapct-CLW decreased. It is probably because of the system characteristics in the watershed as was described in Fig. 2.

Power function in the form of Eq.(6) is used for fitting data. Concentration of each water quality item is estimated from the output of the optical sensor by using the corresponding regression equation. When one function can not cover the whole data of one item, the area was divided into two and the data in each area were fitted separately.

$$
C_{i}=\alpha_{i} X_{j}^{\beta_{i}}+\gamma_{i}
$$

where $i$ stands for each water quality item. $C_{i}$ is concentration of the $i_{t h}$ item, $X_{j}$ is $T b$ for particulate substances and is Chl- $a$ for dissolved substances. $\alpha_{i}$, $\beta_{i}$ and $\gamma_{i}$ are coefficients for the $i_{t h}$ item. The results of regression analysis for major items are shown in Figs. 6(a) and (b) by solid lines with the same color as the spotted data points of water quality. The total load (TL) of $C O D, T P$ and $T N$ can be estimated by,

$$
T L=\sum C_{k} \times Q
$$

where $T L$ is the load of one of $C O D$ (total), TP and $T N$. $C_{k}$ is the concentration of the $k_{t h}$ item which is related to TL. $Q$ is discharge.

Time series of $C O D, T P$ and $T N$ of the Koise River estimated by the proposed method are shown with the blue lines in Fig. 7, while the red dots are the results from the water analysis. Figs. 8(a) and (b) shows the enlarged figures for two flood events in 2005. The agreement between the estimated and measured results suggests that the empirical correlations used in this method are keeping stable during the measurement period.

Fig. 8(c) compares the measurement results during a flood in June 9th in 2006 (red dots) with the estimation by using the correlation obtained in 2005 (blue lines). This figure suggests that the empirical relations obtained above can be used stably in the next year.

The facts mentioned above suggest that the practical measurement technique proposed in this study is useful for monitoring the pollutant load in a river during flood events. In a period of low water, the empirical correlation obtained above might be affected by the seasonal change of farmland condition; however the regular water survey can cover the gradual change of water quality caused by the seasonal factors. In summary, the empirical relations used in the proposed measurement are rather constant, and can be maintained by occasional calibration just as the calibration of $H-Q$ relation for the measurement of river flow rate.

\section{CONCLUSIONS}

The authors think that pursuing scientific knowledge is not the only way to study the dynamic motions in the environment. In actual, we play in daily life depending on a lot of empirical knowledge without any scientific explanation. Being free from a paradigm "more scientific, then better", we might be able to develop a variety of measurement techniques.

In this study, an optical sensor designed to measure turbidity and Chl-a was used. But as mentioned in the text, they are considered as just some signals sent from the environment. Extension of this way of thinking leads to an idea that any increase of the kinds of signals will bring the progress of measurement; introduction of multi-band optical sensor is the next step of this study.

\section{REFERENCES}

1) Japanese Government: Clean Lake Law, Chapter 3, Section 4, 2005.

2) Takahashi, M., Chida, H., Matsuo, S., Examinations of turbidity and water quality at floods in the catchment area of a reservoir, Journal of Hydroscience and Hydraulic Engineering vol.43, pp.593-598, 1999.

3) Yamamoto, K., Futamura, T., Sakano, A.. Estimation of particulate nutrients loads using turbidity meter (in Japanese). Advances in River Engineering vol.9, pp.515-520, 2003

4) Nihei, Y., Hanayama, T., Attempt to measure a periphyton concentration in river water with a fluorometer (in Japanese), Journal of Hydraulic, Coastal and Environmental Engineering No.782/II-70, pp.143-148, 2005.

5) Kato, S., Sato, K., Yoshimura, H., River water quality monitoring by portable ultraviolet photometer case study: Carmona, Cavite Province, Philippines, Annual Report of Mie Prefectural Science and Technology Promotion Center of Public Health and Environment Research Division, vol.48(5), pp.49-54, 2003.

6) Ishikawa, T.: Planning and management of field experiments in Environmental Hydraulics, Training Course of Hydraulics 98-A-4, JSCE, 1998.

7) Kawara, O., Hiryama, K., Kunimatsu, T., A study on pollution loads from the forest and rice paddy feilds, Water Science and Technology, vol.33, No. 4-5, pp.159-165, 1996.

8) Kunihiro, E.: A Study on the Measurement Method of Pollutant Loads from Rivers by Using Optical Water Analyzer, Master Thesis, Tokyo Institute of Technology, 2003.

(Received September 30, 2006) 